\title{
Recombinant SNAP-25 is an effective substrate for Clostridium botulinum type A toxin endopeptidase activity in vitro
}

\author{
Theresa A. N. Ekong, lan M. Feavers and Dorothea Sesardic
}

Division of Bacteriology, National Institute for Biological Standards and Control, South Mimms, Potters Bar, Hertfordshire EN6 3QG, UK
Author for correspondence: Dorothea Sesardic. Tel: +44 1707 654753. Fax: + 441707663796. e-mail: dsesardic@nibsc.ac.uk

Bacterial neurotoxins are now being used routinely for the treatment of neuromuscular conditions. Alternative assays to replace or to complement in vivo bioassay methods for assessment of the safety and potency of these botulinum neurotoxin-based therapeutic products are urgently needed. Advances made in understanding the mode of action of clostridial neurotoxins have provided the basis for the development of alternative mechanism-based assay methods. Thus, the identification of SNAP-25 (synaptosomal-associated protein of molecular mass $\mathbf{2 5} \mathbf{~ k D a )}$ as the intracellular protein target which is selectively cleaved during poisoning by botulinum neurotoxin type A (BoNT/A) has enabled the development of a functional in vitro assay for this toxin. Using recombinant DNA methods, a segment of SNAP-25 (aa residues 134-206) spanning the toxin cleavage site was prepared as a fusion protein to the maltose-binding protein in Escherichia coli. The fusion protein was purified by affinity chromatography and the fragment isolated after cleavage with Factor Xa. Targeted antibodies specific for the $\mathbf{N}$ and $\mathbf{C}$ termini of SNAP-25, as well as the toxin cleavage site, were prepared and used in an immunoassay to demonstrate BoNT/A endopeptidase activity towards recombinant SNAP-25 substrates. The reaction required low concentrations of reducing agents which were inhibitory at higher concentrations as were metal chelators and some inhibitors of metallopeptidases. The endopeptidase assay has proved to be more sensitive than the mouse bioassay for detection of toxin in therapeutic preparations. A good correlation with results obtained in the in vivo bioassay $(r=0.95, n=23)$ was demonstrated. The endopeptidase assay described here may provide a suitable replacement assay for the estimation of the potency of type $\mathrm{A}$ toxin in therapeutic preparations.

Keywords: botulinum neurotoxin type A, endopeptidase assay, recombinant SNAP-25, targeted antibodies

\section{INTRODUCTION}

Botulinum and tetanus neurotoxins are potent neuroparalytic agents which inhibit cholinergic neurotransmission, thereby causing the flaccid and spastic paralyses of botulism and tetanus, respectively (Simpson, 1981; Sakaguchi, 1983). The specific action of botulinum

Abbreviations: BoNT/A, botulinum neurotoxin type A; HRP, horseradish peroxidase; MBP, maltose-binding protein; SNAP-25, synaptosomal-associated protein of molecular mass $25 \mathrm{kDa}$; VAMP, vesicle-associated membrane protein. neurotoxin type A (BoNT/A) is now being exploited in the treatment of certain neuromuscular conditions (Jankovic \& Brin, 1991). The therapeutic preparation consists of minute (ng) quantities of the toxin protein non-covalently associated to form a high molecular mass complex $(900 \mathrm{kDa})$ with non-toxin protein and haemagglutinin components, together with mg quantities of human serum albumin added as bulking agent. The increasing use of BoNT/A presents a number of technical challenges for the measurement of toxin potency in therapeutic preparations. Potency assays for the toxin are critically important for the standardization and control of these substances and, at present, the 
mouse bioassay is the only method sufficiently sensitive to determine the activity of BoNT/A in therapeutic preparations and is the only assay accepted by the regulatory authorities for this purpose. As such, the assay has been identified as a priority target for replacement by the European Centre for the Validation of Alternative Methods (ECVAM) and FRAME (Fund for the Replacement of Animals in Medical Experiments) (Balls \& Straughan, 1996). A number of alternative bioassays are under development which rely on less severe end-points, such as the non-systemic local effect of botulinum toxin described by Pearce et al. (1995) and Sesardic et al. (1996). However, these assays still depend on the use of animals. It is highly desirable to replace these with assays which avoid the use of animals without compromising sensitivity.

Over the last few years, a number of in vitro bioassays for clostridial neurotoxins have been developed. Many of these are immunoassays with sensitivities approaching that of the conventional bioassay, employing either highly specific and sensitive monoclonal antibodies (Shone et al., 1985), or sophisticated amplification systems such as evanescent-wave immunosensors (Kumar et al., 1994) and solid-phase coagulation (Doellgast et al., 1993) or which rely on detection of toxin in the complexed form (Singh et al., 1996). We have also developed a highly sensitive and simple ELISA for the detection of minute quantities of BoNT/A in therapeutic preparations (Ekong et al., 1995). Our studies confirmed that non-functional immunoassays are limited by their inherent inability to differentiate between biologically active and inactive toxin.

Clostridial neurotoxins are now known to be zincdependent metalloendopeptidases (Montecucco \& Schiavo, 1993, 1995) which block the release of neurotransmitters by the specific cleavage of one of the proteins forming the core of the synaptic vesicle dockingfusion complex (Söllner et al., 1993). Thus, tetanus and type $B$ toxins cleave the second isoform of vesicleassociated membrane protein (VAMP, also known as synaptobrevin) at the peptide bond $\mathrm{Gln}_{76}-\mathrm{Phe}_{77}$ (Schiavo et al., 1992; Link et al., 1992). BoNT/A cleaves synaptosomal-associated protein of molecular mass $25 \mathrm{kDa}$ (SNAP-25) at $\mathrm{Gln}_{197}-\mathrm{Arg}_{198}$ (Blasi et al., 1993; Schiavo et al., 1993a, b; Binz et al., 1994). This action of BoNT/A provides a basis for the development of a functional in vitro assay for the toxin utilizing its endopeptidase activity. Such an assay requires a convenient source of purified target protein for use as substrate and a means of monitoring the cleavage of substrate. A number of recent studies have demonstrated that synthetic peptide fragments of VAMP ( $>30$ aa) may be used as in vitro substrates to examine the endopeptidase activity of tetanus and type B neurotoxin (Shone \& Roberts, 1994; Foran et al., 1994). These studies suggest that clostridial neurotoxins require large peptide substrates for the expression of their enzymic activity and that amino acid residues distal from the cleavage site may have an influence on the reaction (Wictome et al., 1996; Soleilhac et al., 1996).
This study describes the preparation of a recombinant

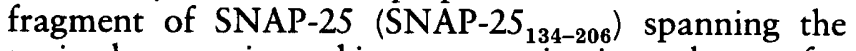
toxin cleavage site and its use as an in vitro substrate for BoNT/A. The recombinant substrate and targeted antibodies were used in an immunoassay to characterize the endopeptidase activity of BoNT/A in purified and therapeutic preparations. The activity of therapeutic preparations of BoNT/A was compared using the endopeptidase assay and the mouse bioassay.

\section{METHODS}

Reagents. A mouse cDNA clone, pSNAP8.52, containing the entire coding region of SNAP-25 was kindly provided by Dr M. C. Wilson of the Scripps Research Institute, La Jolla, CA, USA (Oyler et al., 1989). The expression vector pMAL-c2, amylose resin, restriction endonucleases and Factor Xa were purchased from New England Biolabs and were used as recommended by the manufacturer. Highly purified BoNT/A (specific activity $1.56 \times 10^{8}$ mouse $\mathrm{LD}_{50} \mathrm{mg}^{-1}$ ) was the kind gift of Dr C. C. Shone, CAMR, Porton Down, Salisbury, UK. Other SNAP-25-specific peptides (SNAP-25 ${ }_{1-14}$, SNAP$25_{190-197}$ and SNAP-2 $5_{193-206}$ ) were custom prepared by Genosys Biotechnologies. Except where specified, other reagents were purchased from Sigma. The Escherichia coli strain TB1 [ara $\Delta($ lac-proAB) rpsL ( $\phi 80$ lacZ $\Delta \mathrm{M} 15)$ bsdR] was used as the host for expression of plasmids.

Construction and expression of SNAP-25 fragment as a fusion protein. The nucleotide sequence encoding a region of SNAP-25 spanning the toxin cleavage site (corresponding to aa residues 134-206) was amplified by PCR using the forward primer $5^{\prime}$ GCCATCAGTGGTGAATTCATCCGCAGGGTA and the reverse primer 5 'ACTGATCAAGCTTAACCACTTCCCAGCATC and cloned in the pMAL-c2 expression vector between the EcoRI and HindIII sites (underlined) such that the sequence encoding the SNAP-25 fragment (GenBank accession no. M22012) was in-frame with the malE gene of $E$. coli (Fig. 1). Expression was under the control of the $P_{t a c}$ promoter and the vector encoded the Factor Xa recognition

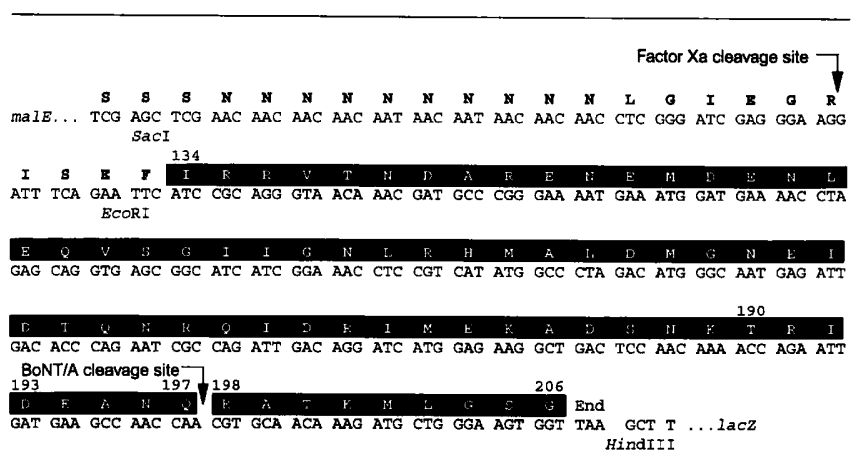

Fig. 1. Cloning and expression of SNAP-25 fused to the $C$ terminus of MalE. The nucleotide sequence encoding the SNAP25 amino acid sequence from residue 134 to 206 was cloned between the EcoRI and HindIII sites at the polylinker of the vector PMAL-c2. The vector-derived nucleotide sequence encoding the linker peptide added to the $C$ terminus of MalE is shown, including the factor $X a$ cleavage site used in the purification of the SNAP-25 peptide from MalE. The position of the BoNT/A cleavage site on the SNAP-25 peptide is also indicated. The gene fusion protein was under the control of a $P_{\text {tac }}$ promoter. 
site between malE and the fused SNAP-25 gene fragment to facilitate subsequent purification of the peptide. The SNAP25-maltose-binding protein (SNAP-25-MBP) fusion protein was expressed by inoculating 1 litre tryptone-yeast broth containing $2 \mathrm{mg}$ glucose $\mathrm{ml}^{-1}$ and $100 \mu \mathrm{g}$ ampicillin ml $\mathrm{m}^{-1}$ with overnight cultures of E. coli cells containing the plasmid. Cells were grown at $37^{\circ} \mathrm{C}$ and expression of fusion protein was induced by the addition of $1 \mathrm{mM}$ IPTG when the $\mathrm{OD}_{600}$ of the culture was about $0 \cdot 6$. Bacteria were harvested by centrifugation $(10 \mathrm{~min}$ at $3000 \mathrm{~g}) 2-24 \mathrm{~h}$ after induction. Longer induction times (up to $24 \mathrm{~h}$ ) improved the yield and did not affect stability of the fusion protein. Pellets were resuspended in $20 \mathrm{mM}$ Tris/ $\mathrm{HCl}, \mathrm{pH} 7 \cdot 0$, containing $0.2 \mathrm{M} \mathrm{NaCl}, 1 \mathrm{mM}$ EDTA, $1 \mathrm{mM}$ PMSF, $1 \mathrm{mM}$ DTT and $1 \mathrm{mM}$ sodium azide (Buffer A) and frozen at $-20^{\circ} \mathrm{C}$ until used. Frozen cells were lysed by sonication (Neu \& Heppel, 1965) and the crude extract collected after centrifugation at $4^{\circ} \mathrm{C}$ for $30 \mathrm{~min}$ at $10000 \mathrm{~g}$.

Purification of the recombinant SNAP-25 fusion protein and SNAP-25 fragment. Cell sonicates containing SNAP-25-MBP fusion protein were resuspended in Buffer $\mathrm{A}$ and applied to an amylose affinity column $(2.5 \times 10 \mathrm{~cm}, 40 \mathrm{ml}$ resin). Unbound material was washed off the column with Buffer $A$ and bound material was specifically eluted with Buffer A containing $10 \mathrm{mM}$ maltose (Buffer B). Column fractions were monitored by $A_{280}$ and SDS-PAGE. Samples containing fusion protein were concentrated to $1 \mathrm{mg} \mathrm{m}^{-1}$ (Amicon Centricon concentrator) and cleaved for $24 \mathrm{~h}$ at room temperature with Factor Xa in Buffer B using a ratio of $0.5 \%(w / w)$ Factor Xa to the fusion protein. The recombinant SNAP-25 fragment was then purified by ultracentrifugation using a Centricon $30 \mathrm{kDa}$ cut-off membrane filter, followed by a Centricon $3 \mathrm{kDa}$ cut-off membrane filter.

Preparation of synaptosomes. Crude synaptosomes were prepared from rat brain by differential sucrose density centrifugation, as described by Huttner et al. (1983).

Production and characterization of antipeptide antibodies. Synthetic peptides of SNAP-25 (corresponding to aa residues 1-14, 190-197 and 193-206) were coupled to keyhole limpet haemocyanin and used to produce the site-specific antibodies R1, R2 and R3, respectively, in rabbits. Adult female New Zealand White rabbits $(2-3 \mathrm{~kg})$ were injected sub-cutaneously with four doses of each immunogen $(300 \mu \mathrm{g}$ per dose) in PBS. Primary injections were carried out in an equal volume of complete Freund's adjuvant and booster injections were carried out in PBS at 4-week intervals. Immune sera were harvested $10 \mathrm{~d}$ after the final injection and purified immunoglobulin prepared by precipitation in ammonium sulphate followed by Protein G affinity chromatography (Pharmacia). Affinity-purified IgG was also prepared using antibody-specific affinity columns prepared by coupling the specific peptide antigen to $\mathrm{CNBr}$-activated Sepharose (Sigma). Antibodies were screened for specificity by Western blotting against crude synaptosomal extracts before and after treatment with purified BoNT/A, and by ELISA using peptide-coated microtitre plates and goat-anti rabbit IgG conjugated to horseradish peroxidase (HRP) (Sigma).

Cleavage of synaptosomal and recombinant SNAP-25 by BoNT/A. The ability of BoNT/A to cleave SNAP-25 in synaptosomes, recombinant SNAP-25 $5_{134-206}$-MBP fusion protein (SNAP-25-MBP), or the recombinant fragment (r-SNAP$\left.25_{134-206}\right)$ was examined. Purified BoNT/A $(0.5 \mathrm{nM}$ or $0.013 \mathrm{nM}$ ), reduced by incubation for $30 \mathrm{~min}$ at $37^{\circ} \mathrm{C}$ with $10 \mathrm{mM}$ DTT or $20 \mathrm{mM} \beta$-mercaptoethanol in $100 \mathrm{mM}$ HEPES, pH 7.4, containing $1.0 \mathrm{mM} \mathrm{NaCl}, 20 \mu \mathrm{M} \mathrm{ZnCl}_{2}$ was used to treat $200 \mu \mathrm{g}$ crude synaptosomes (solubilized with $1 \%$ $n$-octyl- $\beta$-D-glucopyranoside, $200 \mu \mathrm{g}$ SNAP-25-MBP or $50 \mu \mathrm{g}$ $\mathrm{r}$-SNAP-25 $134-206)$. The final reaction volume of $400 \mu \mathrm{l}$ was incubated at $37^{\circ} \mathrm{C}$ and after specified periods of time, $50 \mu \mathrm{l}$ aliquots were transferred to an equal volume of $0.2 \mathrm{M} \mathrm{HCl}$ stop solution. Samples were stored at $-20^{\circ} \mathrm{C}$ prior to analysis by SDS-PAGE and Western blotting.

Characterization of cleavage products. Cleavage mixtures were analysed by SDS-PAGE (Laemmli, 1970) and Western blotting (Towbin et al., 1979), using 10-20\% (v/v) gradient gels. Total protein blots were blocked with PBS containing $0.3 \%$ Tween 20 and stained with colloidal gold. Immunoblots were blocked with $5 \%(\mathrm{w} / \mathrm{v})$ skimmed milk (Marvel) in PBS containing $0.05 \%$ Tween 20 (PBST) and incubated with $1 \mu \mathrm{g}$ of either the R3 or R2 affinity-purified polyclonal antibodies $\mathrm{ml}^{-1}$, specific either for the parent substrate (SNAP-25 ${ }_{1-206}$, SNAP-25-MBP or r-SNAP-25 ${ }_{134-206}$ ) or for the N-terminal cleavage product (SNAP-25 ${ }_{1-197}$ or SNAP-2 $5_{134-197}$ ), respectively. The second antibody (affinity-purified goat anti-rabbit IgG coupled to HRP) was used at a dilution of $1 / 2000$ and immobilized antigens were visualized with the Sigma Fast DAB (diaminobenzidine) substrate system.

Cleavage products were also characterized by mass spectrometry and N-terminal sequence analysis of the minor $\mathrm{C}$ terminal metabolite (SNAP-25 ${ }_{188-206}$ ) following purification by reverse-phase HPLC (Ekong et al., 1997). N-terminal sequence analysis was performed by Dr D. Pappin of the Imperial Cancer Research Fund, Lincoln's Inn Field, London.

Assessment of BoNT/Ainduced proteolytic cleavage of recombinant SNAP-25 by ELISA. An enzyme-immunoassay was developed to assess the endopeptidase activity of BoNT/A towards the recombinant substrates SNAP-25-MBP and $r-$ SNAP-25 ${ }_{134-206}$. Wells of microtitre plates were coated with $2 \mu \mathrm{g}$ substrate $\mathrm{ml}^{-1}$ in coating buffer $\left(0.05 \mathrm{M} \mathrm{NaCO}_{3}, \mathrm{pH} 9.6\right)$ for $16 \mathrm{~h}$ at $4{ }^{\circ} \mathrm{C}$. Non-specific adsorbtion sites were blocked for $1 \mathrm{~h}$ at $37^{\circ} \mathrm{C}$ with $5 \%$ skimmed milk in PBST. Plates were then incubated with serial dilutions of the reduced purified neurotoxin in $50 \mathrm{mM}$ HEPES buffer containing $2 \mathrm{mM}$ DTT and $20 \mu \mathrm{M} \mathrm{ZnCl}$ at $37^{\circ} \mathrm{C}$. After washing, BoNT/A-cleaved SNAP-25 was detected by incubation with $5 \mu \mathrm{g}$ R 2 primary antibody $\mathrm{ml}^{-1}$, followed by a $1 / 2000$ dilution of goat antirabbit IgG conjugated to HRP ( $90 \mathrm{~min}$ incubation each at $37^{\circ} \mathrm{C}$ ). Dilutions of detection antibodies were made in PBST containing $2.5 \%$ skimmed milk. Finally, the substrate solution

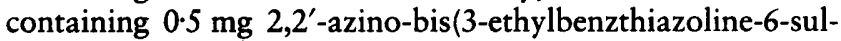
phonic acid) $\mathrm{ml}^{-1}$ (ABTS) and $0.04 \% \mathrm{H}_{2} \mathrm{O}_{2}$ in $0.05 \mathrm{M}$ citric acid, pH 4.0, was added. Colour was allowed to develop at room temperature for $30 \mathrm{~min}$ and $A_{4.5}$ was measured.

To optimize the microtitre-based endopeptidase assay, the influence of time, $\mathrm{pH}$, buffers, ionic strength, temperature and potential inhibitors on the activity of BoNT/A was examined. Wells of microtitre plates were sensitized with SNAP-25-MBP and incubated under different conditions with serial dilutions of reduced purified BoNT/A (initial dilution $0.5 \mathrm{nM}$ ). BoNT/A-cleaved SNAP-25 was detected as described above and the extent of cleavage was expressed as a percentage of the control value obtained with $50 \mathrm{mM}$ HEPES, pH 7.0, containing $2 \mathrm{mM}$ DTT and $20 \mu \mathrm{M} \mathrm{ZnCl}$.

Measurement of the endopeptidase activity of therapeutic BoNT/A. The endopeptidase activity of therapeutic preparations of BoNT/A was determined using the optimized enzymeimmunoassay. Therapeutic preparations of BoNT/A were pre-reduced by incubating one vial with $0.5 \mathrm{ml} 50 \mathrm{mM}$ HEPES, pH 7.0, containing $10 \mathrm{mM}$ DTT and $20 \mu \mathrm{M} \mathrm{ZnCl}_{2}\left(37^{\circ} \mathrm{C}\right.$ for $30 \mathrm{~min})$. This was diluted to $2 \mathrm{mM}$ DTT in the reaction buffer 
and added in serial dilutions to wells of microtitre plates previously sensitized with SNAP-25-MBP for $60 \mathrm{~min}$ at $37^{\circ} \mathrm{C}$. BoNT/A-cleaved SNAP-25-MBP was detected immunologically as described above and the extent of cleavage was expressed in relation to the cleavage detected with a reference preparation comprising an in-house standard of BoNT/A preparation.

Bioassay. The potency estimates of therapeutic preparations of BoNT/A were performed using the methods described by Sesardic et al. (1996) and McLellan et al. (1996) for routine control of this product and were all expressed as activity against an in-house standard used as a reference.

\section{RESULTS}

\section{Expression and purification of fusion protein and recombinant SNAP-25 fragment}

Cytoplasmic extracts from induced cultures were found to contain larger amounts of a $49 \mathrm{kDa}$ protein than extracts from uninduced cultures (data not shown). The size of the protein band was consistent with the fusion of MBP and the SNAP-25 $5_{134-206}$ fragment (molecular masses of 42 and $7 \mathrm{kDa}$, respectively). Maximum expression of fusion protein was observed $24 \mathrm{~h}$ after induction and was estimated to constitute about 10-20 $\%$ of total soluble cellular extract as measured by densitometry (UVP gel documentation package SW2000, Cambridge).

Cytoplasmic extracts from $E$. coli harbouring the SNAP25 gene product were fractionated by chromatography on an amylose affinity column. The eluate consisted of $30-40 \%$ fusion protein (the rest being free MBP) (Fig. 2). To prepare SNAP-25 $5_{134-206}$, the column eluate was treated with Factor $\mathrm{Xa}$ and the SNAP-25 fragment purified by ultrafiltration through a Centricon filter. The fragment, which was not readily stained with colloidal gold, was visible on immunoblots only with the R3 antibody, specific for the intact SNAP-25 (Fig. 2). Steps in the purification and the yields of protein are shown in Table 1. Typically, 55-80 mg MBP/SNAP-25-MBP (with SNAP-25-MBP purity of $30-40 \%$ ) and $2-4.5 \mathrm{mg}$ SNAP- $25_{134-206}$ (purity $100 \%$ ) was obtained from cell lysates containing about $900 \mathrm{mg}$ total protein.

\section{Production of antibodies specific for intact and BoNT/A-cleaved SNAP-25}

Rabbit polyclonal antiserum (R1, R2 and R3) to peptides SNAP-25 $5_{1-14}$, SNAP-25 ${ }_{190-197}$ and SNAP-25 ${ }_{193-206}$, were prepared and antibody titres were examined by ELISA using antigen-coated plates. Antibody titres ranged from

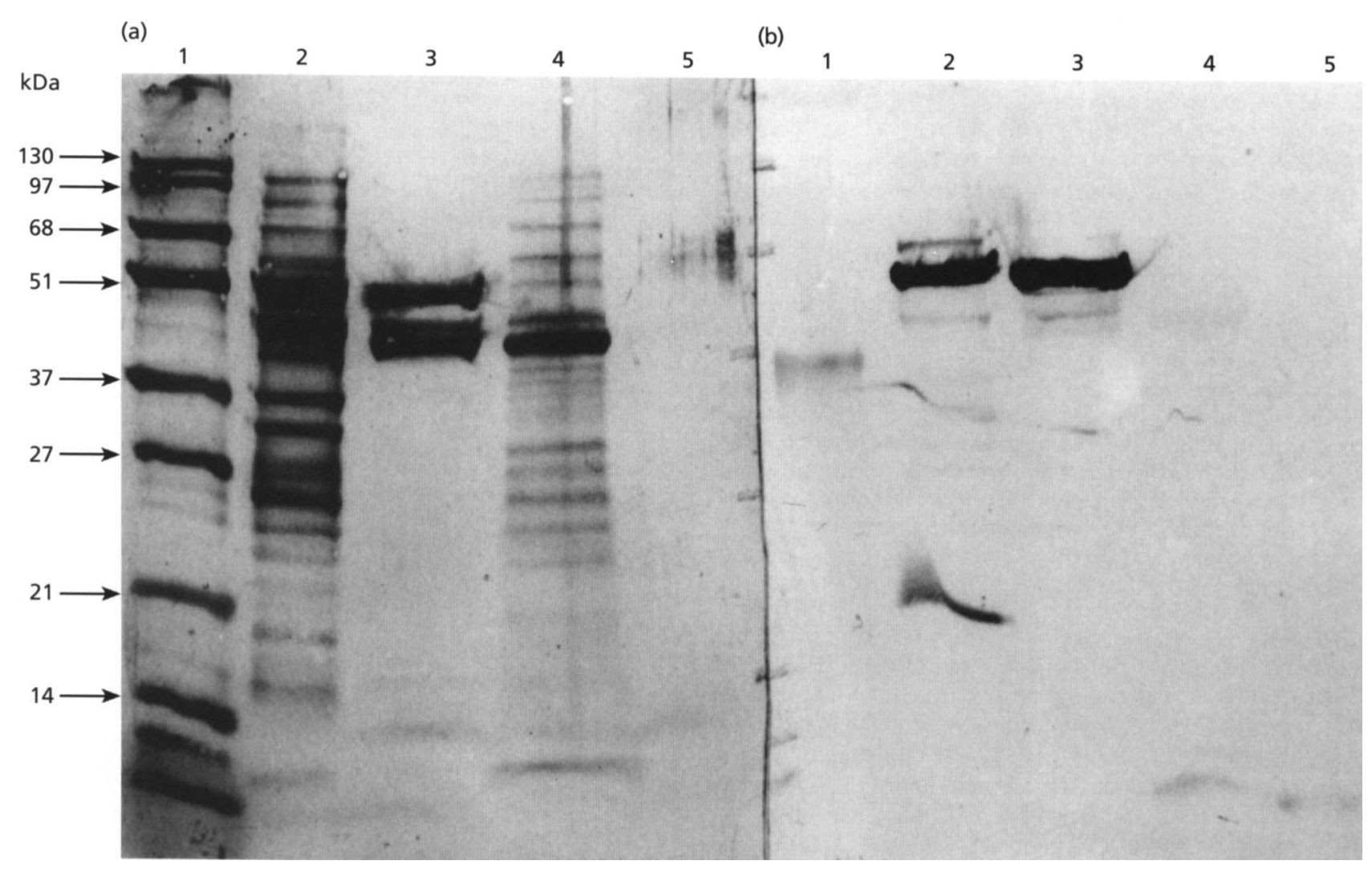

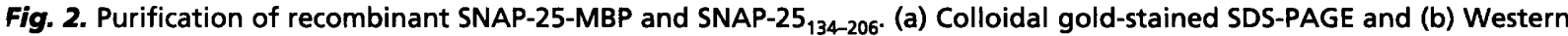
blot using anti-SNAP-25 ${ }_{190-197}$ (R2) antibody of: lane 1, molecular mass markers; 2 , crude lysate from trypsinized $E$. coli; 3 , amylose column eluate containing a mixture of fusion protein and free MBP; 4, a mixture of products of Factor Xa cleavage; 5, purified SNAP-25 fragment. SDS-PAGE was carried out in 10-20\% gradient gels under reducing conditions. 
Table 1. Purification of fusion protein and recombinant SNAP-25 fragment

\begin{tabular}{|lccc|}
\hline Step & $\begin{array}{c}\text { Total protein } \\
(\mathbf{m g})\end{array}$ & $\begin{array}{c}\text { Yield } \\
(\mathbf{m g})\end{array}$ & $\begin{array}{c}\text { Purity after SDS-PAGE } \\
(\%)\end{array}$ \\
\hline E. coli cell lysate & 598 & 100 & $<5$ \\
SNAP-25-MBP & 100 & $10 \cdot 2$ & $30-40$ \\
SNAP-25 fragment & $2 \cdot 5$ & $0 \cdot 42$ & 100 \\
\hline
\end{tabular}

Table 2. ELISA titres of anti-SNAP-25 antipeptide antibodies

\begin{tabular}{|c|c|c|c|}
\hline Antibody & $\begin{array}{l}\text { SNAP-25 } \\
\text { sequence }\end{array}$ & Specificity & $\begin{array}{c}\text { Titre } \\
\left(\mu \mathrm{g} \mathrm{ml}^{-1}\right) \dagger\end{array}$ \\
\hline R1 (serum) & $1-14$ & SNAP-25 (N-terminal) & 40 \\
\hline R1 (AP-IgG) & $1-14$ & SNAP-25 (N-terminal) & $1 \cdot 70$ \\
\hline R2 (serum) & 190-197 & $\begin{array}{l}\text { BoNT/A cleavage product of } \\
\text { SNAP-25 (N-terminal) }\end{array}$ & $4 \cdot 70$ \\
\hline R2 (AP-IgG) & 190-197 & $\begin{array}{l}\text { BoNT/A cleavage product of } \\
\text { SNAP-25 (N-terminal) }\end{array}$ & 0.20 \\
\hline R3 (serum) & 193-206 & SNAP-25 (C-terminal) & $1 \cdot 10$ \\
\hline R3 (AP-IgG) & 193-206 & SNAP-25 (C-terminal) & 0.08 \\
\hline
\end{tabular}

*AP-IgG, Affinity-purified IgG.

†Antibody concentration at an $A_{405}$ of $1 \cdot 0$.

8-40 $\mu \mathrm{g}$ protein $\mathrm{ml}^{-1}$ for the crude antiserum to $0 \cdot 08$ $1 \cdot 1 \mu \mathrm{g}$ protein $\mathrm{ml}^{-1}$ for affinity purified IgG (Table 2 ). Specificity of antibodies was also examined by Western blotting. The $\mathrm{R} 1$ antibody recognized a band of about $27 \mathrm{kDa}$ in crude synaptosomal preparations, corresponding to native SNAP-25, but as expected it did not recognize the recombinant fusion protein or fragment (data not shown). The R3 antibody, however, recognized both the native SNAP-25 in crude synaptosomes and the recombinant SNAP-25 substrates (SNAP-25MBP and r-SNAP-25 ${ }_{134-206}$ ) (Fig. 2), with apparent molecular masses of 50 and $8 \mathrm{kDa}$, respectively. The R2 antibody was not reactive with native or recombinant SNAP-25 substrates in samples which had not been treated with toxin, but recognized a major band with a molecular mass similar to that of the parent substrate after treatment with type A toxin (shown in Fig. 3 for SNAP-25-MBP). The specificity and titres of the antibodies to SNAP-25 are as summarized in Table 2 .

\section{Characterization of the endopeptidase activity of BoNT/A}

The proteolytic cleavage of native (data not shown) and recombinant SNAP-25 by purified BoNT/A was assessed by Western blotting. Native SNAP-25 in crude synaptosomes (permeabilized with $1 \% n$-octyl- $\beta$-Dglucopyranoside) and the recombinant SNAP-25 substrates were cleaved by purified BoNT/A with loss of reactivity to the $\mathrm{R} 3$ antibody, specific for intact substrate, and a concomitant gain in reactivity to the $\mathrm{R} 2$ antibody, specific for cleaved substrate (Fig. 3). These results indicate that BoNT/A cleaves recombinant
SNAP-25, resulting in the formation of an epitope (SNAP-25 ${ }_{190-197}$ ) which is recognized by the R2 antibody. Confirmation that the specific peptide bond $\mathrm{Gln}_{197}-\mathrm{Arg}_{198}$ was cleaved by BoNT/A in the SNAP$25_{134-206}$ fragment was achieved by $\mathrm{N}$-terminal sequence analysis and electrospray mass spectroscopy of the Cterminal SNAP-25 ${ }_{198-206}$ metabolite isolated by reversephase HPLC, giving the expected sequence and mass of 920.1 Da (extrapolated 920.7 Da) (data not shown).

The influence of a number of different conditions on the endopeptidase activity of purified BoNT/A towards SNAP-25-MBP was examined using microtitre plates sensitized with this reagent. The time course of cleavage by BoNT/A was typical of an enzyme reaction: there was an increase in the rate of cleavage which was linear initially, but decreased later due to depletion of substrate and/or accumulation of product (data not shown). This increase in the initial rate of cleavage was inhibited by $75 \%$ on the inclusion of $2 \mathrm{mM}$ EDTA in the cleavage buffer. There was an absolute requirement for reduction of toxin and no cleavage was observed if reducing agent (10 mM DTT or $20 \mathrm{mM} \beta$-mercaptoethanol) was omitted from buffers. Although cleavage was observed when reducing agent was added at the beginning of the reaction without prior reduction of toxin, this was preceded by a lag period (10-40 min depending on the reducing agent and its concentration). This lag period was eliminated by treating toxin with reducing agent prior to cleavage reaction. The optimum time for toxin pre-reduction with $10 \mathrm{mM}$ DTT was $30 \mathrm{~min}$ at $37^{\circ} \mathrm{C}$ with $70 \%$ of maximum observed cleavage rate determined at time 0 and $35 \%$ determined at $2 \mathrm{~h}$. 
(a)
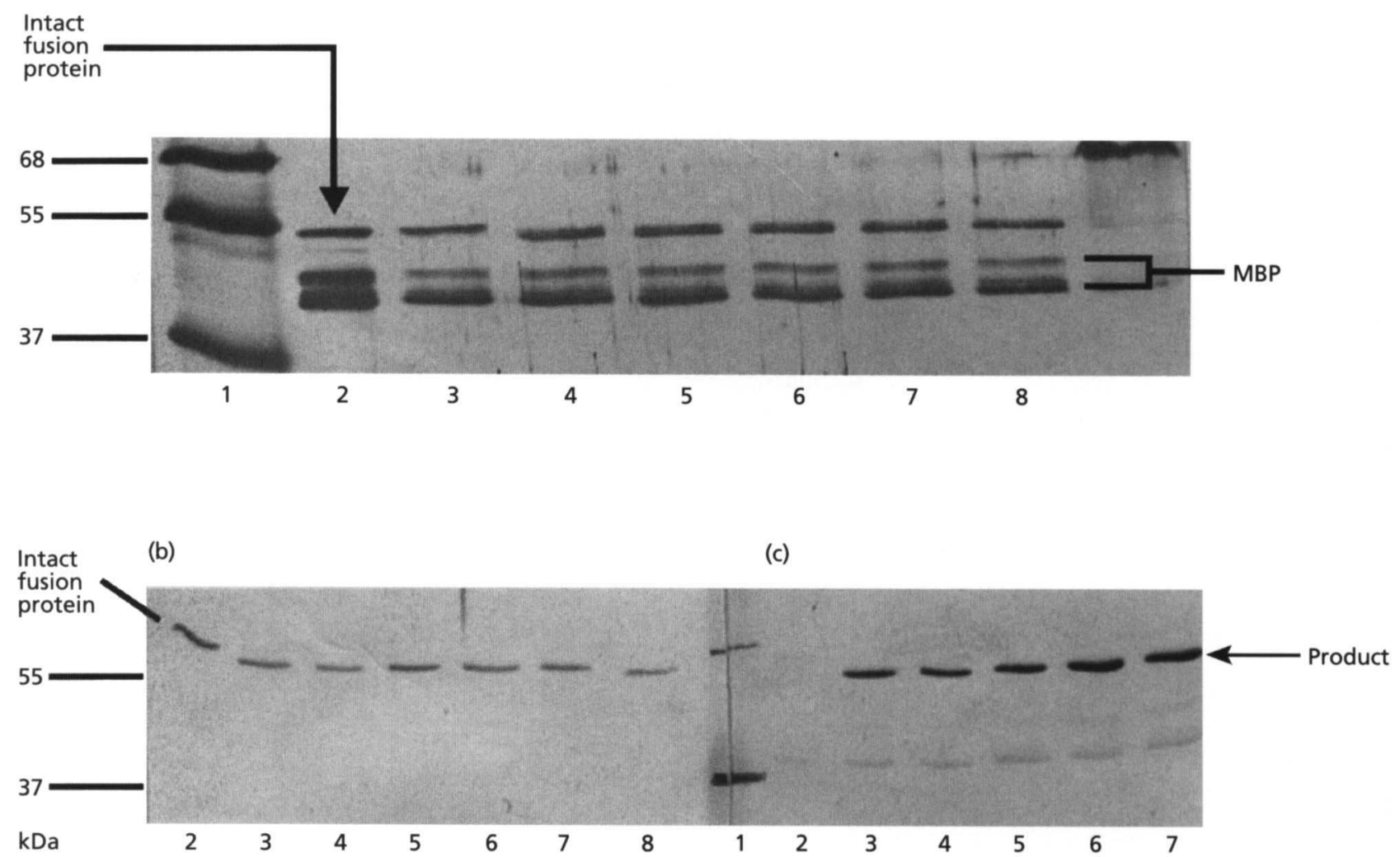

Fig. 3. Time course for proteolytic cleavage of recombinant SNAP-25 by purified BoNT/A. SDS-PAGE and immunoblotting of the recombinant SNAP-25 were performed following incubation with purified BoNT/A for up to 240 min. SDS-PAGE was carried out on $12 \%$ gels followed by transfer to nitrocellulose membrane and (a) staining with colloidal gold, (b)

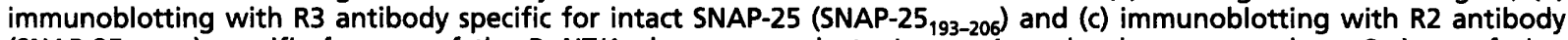
(SNAP-25, 1907 ) specific for one of the BoNT/A cleavage products. Lanes: 1 , molecular mass markers; 2 , intact fusion protein $(t=0)$; 3-8, SNAP-25-MBP treated with purified BoNT/A toxin for 15, 30, 60, 120, 180 and 240 min, respectively.

Table 3. Effect of buffers on the cleavage of SNAP-25-MBP by BoNT/A

Wells of microtitre plates were sensitized with SNAP-25-MBP $\left(2 \mu \mathrm{g} \mathrm{ml}^{-1}\right)$ and treated with serial dilutions of reduced purified BoNT/A (initial dilution $=0 \cdot 013 \mathrm{nM}$ ) diluted in different buffers, $\mathrm{pH} 7 \cdot 0$, with $2 \mathrm{mM}$ DTT and $20 \mu \mathrm{M} \mathrm{ZnCl}$. Values represent the mean activity \pm sD for six independent determinations expressed as a percentage of activity in $50 \mathrm{mM}$ HEPES buffer, $\mathrm{pH} 7 \cdot 0$, with $2 \mathrm{mM}$ DTT and $20 \mu \mathrm{M} \mathrm{ZnCl}_{2}$.

\begin{tabular}{|lcc|}
\hline Buffer & $\begin{array}{c}\text { Concentration } \\
(\mathrm{mM})\end{array}$ & $\begin{array}{c}\text { Cleavage of SNAP-25-MBP } \\
\text { (percentage of control activity) }\end{array}$ \\
\hline HEPES & 50 & 100 \\
HEPES & 100 & $85 \pm 8 \cdot 9$ \\
HEPES & 200 & $45 \pm 10 \cdot 2$ \\
Triethanolamine & 50 & $59 \pm 6 \cdot 1$ \\
Tris/HCl & 50 & $47 \pm 8 \cdot 5$ \\
Sodium phosphate & 50 & $6 \pm 3 \cdot 4$ \\
\hline
\end{tabular}

Following toxin reduction, the presence of low levels of reducing agent in the reaction buffer $(2-5 \mathrm{mM})$ was required to maintain high rates of cleavage. Higher initial rates (two- to fourfold) of cleavage were observed when DTT was used rather than $\beta$-mercaptoethanol.
The cleavage of SNAP-25-MBP by BoNT/A was influenced by the type and concentration of buffer used in the reaction. Table 3 shows the rates of reaction with various buffers at $\mathrm{pH} 7 \cdot 0$. Rates of cleavage observed with triethanolamine, $\mathrm{Tris} / \mathrm{HCl}$ and, in particular, 
sodium phosphate buffers, were lower than those observed with HEPES buffers. Increasing the concentration of HEPES buffer from 50 to $20 \mathrm{mM}$ had a marked inhibitory effect on the cleavage rate.

Optimal endopeptidase activity of BoNT/A towards the substrate was observed at $\mathrm{pH} 7 \cdot 0$; there was a rapid decrease in the rate of cleavage on either side of this $\mathrm{pH}$. The endopeptidase activity of $\mathrm{BoNT} / \mathrm{A}$ was also strongly inhibited by an increase in the ionic strength of the buffer. An increase in the concentration of $\mathrm{NaCl}$ from 0 to $50 \mathrm{mM}$ and to $100 \mathrm{mM}$ resulted in a decrease of 60 and $87 \%$, respectively. Optimum reactions were considered to be in $50 \mathrm{mM}$ HEPES buffer, $\mathrm{pH} 7 \cdot 0$, containing $2 \mathrm{mM}$ DTT and $20 \mu \mathrm{M} \quad \mathrm{ZnCl}_{2}$ without sodium chloride (data not shown).

The temperature profile for BoNT/A proteolytic activity was bell-shaped, with an optimum at $37^{\circ} \mathrm{C}$; there was no reaction at $0{ }^{\circ} \mathrm{C}$ and the rate of the reaction decreased rapidly beyond $37^{\circ} \mathrm{C}$ (data not shown). Preincubation of reduced purified toxin $(0.013 \mathrm{nM})$ for 30 and $120 \mathrm{~min}$ at $37^{\circ} \mathrm{C}$ prior to initiation of reaction resulted in a 40 and $85 \%$ loss of activity, respectively.

\section{Effect of inhibitors}

The effect of a number of inhibitors on the endopeptidase activity of BoNT/A was assessed. For these reactions, reduced toxin was pre-incubated for $30 \mathrm{~min}$ at $37^{\circ} \mathrm{C}$ with twice the concentration of potential inhibitor required in the final reaction mixture. Wells of substrate-coated plates were then treated for different periods of time with the toxin/inhibitor mixture at $37^{\circ} \mathrm{C}$. The results are presented in Table 4. High concentrations of metal ion chelators such as EDTA $(5 \mathrm{mM})$ or 1,10 -o-phenanthroline $(1.2 \mathrm{mM})$ and divalent cations such as $\mathrm{Zn}^{2+}(0.5 \mathrm{mM})$ completely inhibited the activity of BoNT/A, while the reducing agent DTT, which has weak metal-chelating activity, was inhibitory above $10 \mathrm{mM}$. This profile confirms the zinc-dependent metalloprotease activity of BoNT/A towards the recombinant substrate.

\section{Assessment of the proteolytic activity of therapeutic BONT/A}

The enzyme-immunoassay employing microtitre plates sensitized with SNAP-25-MBP or SNAP-25 ${ }_{134-206}$ was used to estimate the endopeptidase activity of therapeutic preparations of BoNT/A. Titration curves for three different therapeutic preparations, including an inhouse reference standard, showed good dose-response profiles (Fig. $4 \mathrm{a}$ ) in the dilution range equivalent to $1.0-31.6$ mouse $\mathrm{LD}_{50} \mathrm{ml}^{-1}$. The minimum level of toxin activity that could be detected ranged from 0.1 to 0.8 mouse $\mathrm{LD}_{50} \mathrm{ml}^{-1}(n=16)$. Different therapeutic preparations of BoNT/A were compared for their relative activities determined by the endopeptidase assay and the in vivo bioassay. There was a very good correlation between toxin activity detected by the two systems employing either SNAP-25-MBP $(r=0.95, n=23$, slope $=1.03 ;$ Fig. 4 b $)$ or SNAP-25 $5_{134-206}(r=0.96$, $n=16$, slope $=1$; data not shown).

\section{DISCUSSION}

The fact that clostridial neurotoxins are highly specific zinc-endopeptidases which selectively target different components of the synaptic vesicle/synaptic membrane docking system offers an attractive basis for the development of in vitro assays for toxin detection. As BoNT/A selectively targets SNAP-25, at position 197-198, we expressed a SNAP-25 fragment (sequence 134-206) incorporating this cleavage site as a fusion protein with MBP in $E$. coli using the pMAL-c2 expression vector which facilitated subsequent purification of the recombinant protein (SNAP-25-MBP) by amylose-based affinity chromatography. The yield of protein eluting from the amylose column was high (up to $60 \mathrm{mg}$ in some preparations) and consisted of approximately $40 \%$ free MBP which was in agreement with observations noted by other workers ( $\mathrm{Li}$ et al., 1994; Fukuoka et al., 1993). Most importantly, the fusion protein of SNAP-25-MBP was effectively cleaved by BoNT/A and the presence of free MBP did not apparently interfere with endopeptidase activity. Good yields of purified SNAP-25 $5_{134-206}$ peptide [0.9-2.1 mg (1 culture medium $)^{-1}$ ] could be obtained by cleavage of the fusion protein with Factor $\mathrm{Xa}$ and further purification by ultracentrifugation. Based on these results, the pMAL-c2 system is suitable for the preparation of recombinant SNAP-25 for use in the development of an endopeptidase assay for the in vitro detection of BoNT/A activity.

Recombinant fusion protein SNAP-25-MBP and SNAP$25_{134-206}$ peptide were both efficiently cleaved by purified BoNT/A and by this toxin in therapeutic formulations. That BoNT/A was able to cleave recombinant SNAP-25 at position $\mathrm{Gln}_{197}-\mathrm{Arg}_{198}$ was confirmed by Western blotting using an antibody targeted to an epitope on SNAP-25 which is created only after cleavage with the type A toxin (190-197). Whereas anti-peptide antibody to SNAP-25 ${ }_{1-14}$ reacted with both intact and BoNT/Acleaved SNAP-25, antibody to SNAP- $25_{190-197}$ reacted selectively with the BoNT/A-cleaved SNAP- 25 peptide, making it a selective detecting reagent in the microtitrebased endopeptidase assay described here.

Further confirmation that BoNT/A cleaved recombinant SNAP-25 at position $\mathrm{Gln}_{197}-\mathrm{Arg}_{198}$ was obtained by mass spectrometric and $\mathrm{N}$-terminal sequence analysis of the putative 9 aa product of the reaction (Ekong $e t$ al., 1997) and was in agreement with other studies (Schiavo et al., 1993a, b).

A microtitre-based endopeptidase assay for BoNT/A activity was developed using the recombinant substrate and targeted antibodies. A large number of assay conditions utilizing both purified BoNT/A and therapeutic formulations were investigated. These experiments confirmed that the toxin needed to be reduced, either with DTT or $\beta$-mercaptoethanol, for effective 
Table 4. Effect of inhibitors on the cleavage of recombinant SNAP-25 by BoNT/A

Reduced purified BoNT/A $(0.013 \mathrm{nM})$ was incubated for $3 \mathrm{~min}$ at $37^{\circ} \mathrm{C}$ with twice the concentration of inhibitor required in the final reaction made up in HEPES buffer, $\mathrm{pH} 7 \cdot 0,2 \mathrm{mM}$ DTT and $20 \mu \mathrm{M} \mathrm{ZnCl}_{2}$. Serial dilutions of toxin/inhibitor mixture were used to treat wells of a SNAP-25-MBP-sensitized microtitre plate for $60 \mathrm{~min}$ at $37^{\circ} \mathrm{C}$. Activity was expressed as a percentage of that in the absence of inhibitors and represents the mean of two independent determinations.

\begin{tabular}{|lcc|}
\hline Inhibitor & $\begin{array}{c}\text { Concentration } \\
(\mathrm{mM})\end{array}$ & $\begin{array}{c}\text { Cleavage of r-SNAP-25 } \\
\text { (percentage of control) }\end{array}$ \\
\hline None & - & 100 \\
DTT & 10 & 105 \\
EDTA & 50 & $61 \cdot 0$ \\
& 2 & $9 \cdot 1$ \\
Captopril & 5 & 0 \\
& 2 & $96 \cdot 6$ \\
o-Phenanthroline & 10 & $23 \cdot 3$ \\
& 15 & $4 \cdot 5$ \\
Phosphoramidon & $0 \cdot 13$ & $26 \cdot 7$ \\
Zn $^{2+}$ & $0 \cdot 50$ & $3 \cdot 5$ \\
& 2 & 110 \\
& $0 \cdot 20$ & 98 \\
\hline
\end{tabular}

endopeptidase activity. These results suggest that only the two-chain form of the toxin, in which the inter-chain disulphide bond has been reduced, has appreciable proteolytic activity, as is the case for other clostridial neurotoxins (Schiavo et al., 1993b; Shone \& Roberts, 1994; Foran et al., 1994; Hallis et al., 1996) and as shown recently for BoNT/A (Schmidt \& Bostian, 1995). In agreement with the observations of Schmidt \& Bostian (1995), increasing the concentration of DTT from optimum $(10 \mathrm{mM})$ to $50 \mathrm{mM}$ inhibited $61 \%$ of activity, due most likely to the weak metal chelating activity of DTT. Similarly, consistent with the inhibitory profiles of zinc-dependent endopeptidases (Schiavo et al., 1992, 1993a) $\mathrm{Zn}^{2+}$ and metal-ion chelators such as EDTA inhibited $>90 \%$ of the proteolytic activity of BoNT/A at $2 \mathrm{mM}$ and $500 \mu \mathrm{M}$ respectively. The effects of recognized inhibitors of metallopeptidases were also studied. Whereas o-phenanthroline inhibited $>90 \%$ activity at $500 \mu \mathrm{M}$, phosphoramidon and captopril were less inhibitory, with virtually no loss of activity at $2 \mathrm{mM}$, in agreement with their low inhibitory effect against the peptidase activity of tetanus light chain on its natural substrate, VAMP (Soleilhac et al., 1996).

The endopeptidase activity of purified BoNT/A and this toxin in therapeutic formulations showed a bell-shaped $\mathrm{pH}$ profile, with an optimum at $\mathrm{pH} 7.0$ for both preparations. Since co-ordination of a zinc molecule by histidine residues within the active site of the toxin enzyme is thought to be crucial for catalytic activity (Schiavo et al., 1992, 1993a), the reduced activity observed at $\mathrm{pH} 6.0$ could reflect changes in the ionization state of these histidine moieties. At the other end of the spectrum, the reduction in activity above $\mathrm{pH} 7.5$ most likely reflects decreased stability of the toxin apoprotein which is known to be labile above pH 7.3 (Schantz \& Johnson, 1992).

The use of synthetic peptides as substrates in in vitro assays for clostridial neurotoxins has recently been addressed by several workers. A fluorescence-based assay for determination of tetanus toxin peptidase activity using HPLC was described by Soleilhac et al. (1996) and HPLC was also used to characterize botulinum type B (Wictome et al., 1996) and botulinum type A (Schmidt \& Bostian, 1995; Ekong et al., 1997) endopeptidase activity in vitro. These assays have been useful in confirming the kinetics and optimum conditions for the endopeptidase cleavage reaction. In particular, such assays have confirmed the number and identity of the critical residues necessary for substrate design. However, such assays are less useful in the rapid laboratory detection of toxin and at present do not provide the sensitivity required for detection of samples with low toxin activity such as clinical formulations. Thus, the assay for type A toxin described by Schmidt \& Bostian (1995) requires 5-30 $\mu \mathrm{g}$ pure type A toxin $\mathrm{ml}^{-1}$ in the reaction.

A microtitre-based endopeptidase assay for type A toxin has been recently described by Hallis et al. (1996) using a synthetic peptide of SNAP-25 $5_{137-206}$, comparable in size with the recombinant peptide described here. The detection limit for purified type A toxin was described as $1 \cdot 3 \pm 0 \cdot 25 \mathrm{ng} \mathrm{ml}^{-1}$, equivalent to approximately 200 mouse $\mathrm{LD}_{50} \mathrm{ml}^{-1}$ for this toxin. The enzymic amplification of the assay increased the sensitivity tenfold (Hallis et al., 1996). Even without an amplification system we were able to detect the equivalent of $0 \cdot 2-1 \cdot 0$ 
(a)

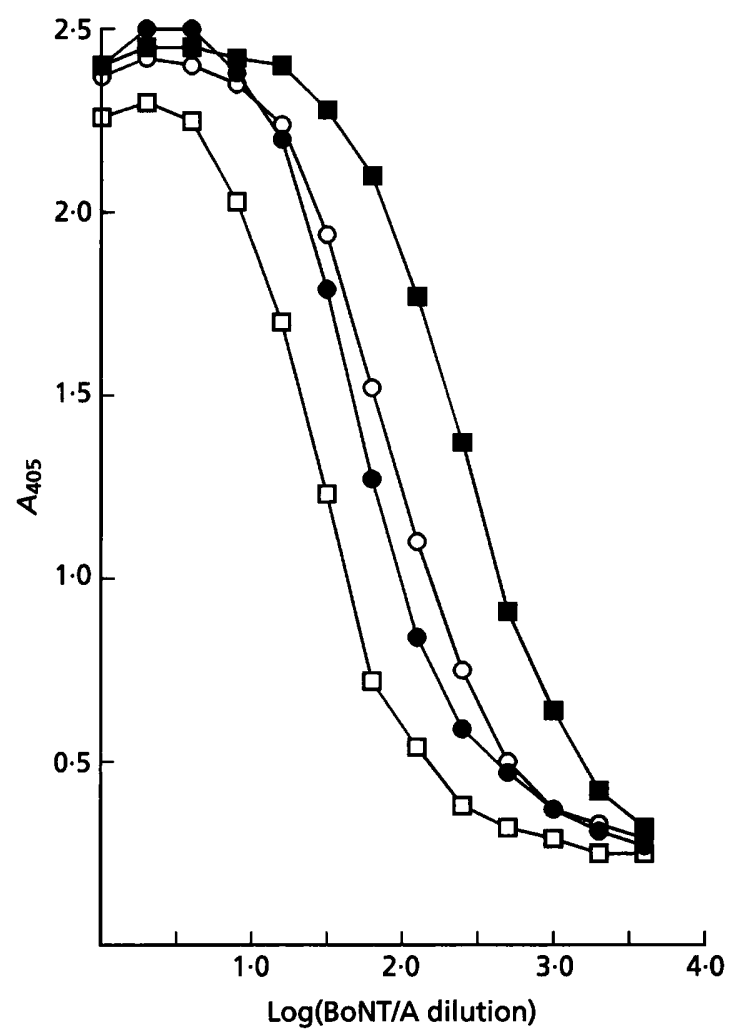

(b)

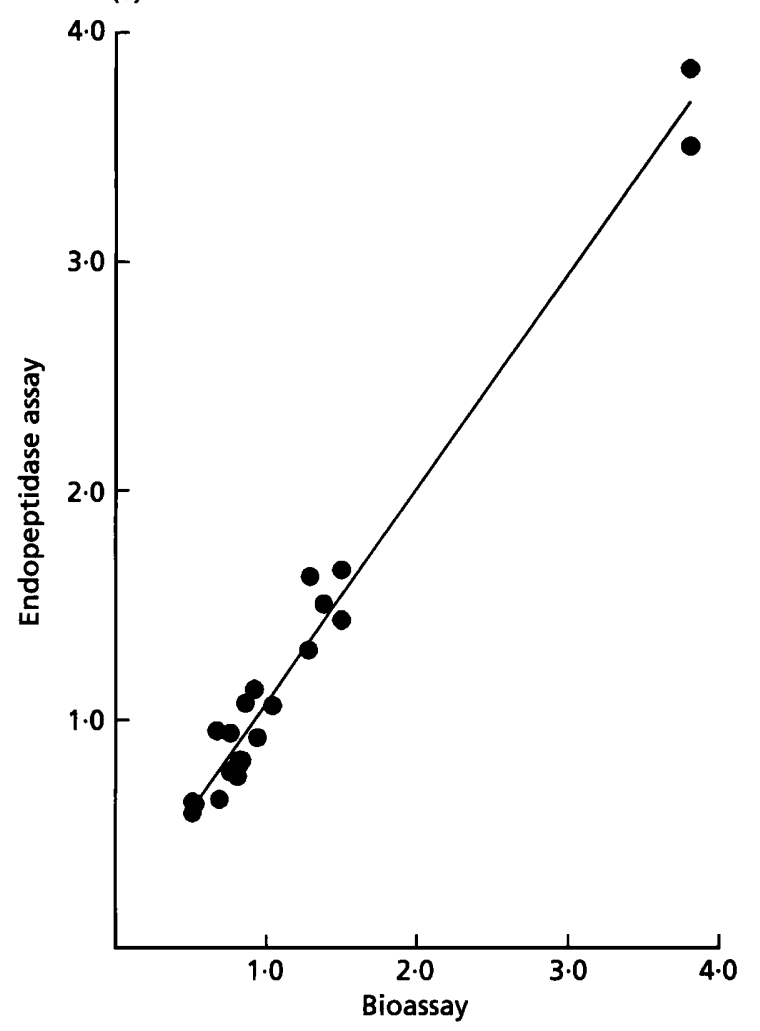

Fig. 4. Endopeptidase activity of therapeutic preparations of BoNT/A. (a) Microtitre plates sensitized with SNAP-25-MBP were treated with serial dilutions (initial dilution $=2 \mathrm{ml}$ per vial) of three different therapeutic preparations of BoNT/A $(\square, 1 \times ; 0$, mouse $\mathrm{LD}_{50} \mathrm{ml}^{-1}$ for BoNT/A in purified and clinical preparations, making this the most sensitive in vitro assay for detection of biologically active BoNT/A.

As the major factor determining the sensitivity of such an assay is the rate of cleavage of the synthetic peptide (Hallis et al., 1996) it is possible that the conditions used in this presentation are more favourable. It is unlikely that the amount of peptide bound to the wells of microtitre plates will affect the rate of cleavage reaction. This was confirmed by the similar activity profiles obtained for SNAP-25-MBP, containing up to $40 \%$ free $\mathrm{MBP}$, and purified peptide of SNAP-2 $5_{134-206}$. The optimum buffer for toxin activity was similar to that reported by Hallis et al. (1996) but preparation of substrate, its binding to the microtitre plates via Cys residues, higher concentration of DTT in the reaction and use of $1 \%$ foetal serum albumin were different. Although we did confirm that inclusion of serum albumin at concentrations of $1-5 \mathrm{mg} \mathrm{m}^{-1}$ can favour the endopeptidase reaction, higher concentrations can be inhibitory. In agreement with Schmidt \& Bostian (1995) we have also confirmed that increasing the molarity of HEPES buffer and substituting HEPES buffer with triethanolamine, Tris or phosphate will all substantially decrease the catalytic activity of the toxin. Many factors have been shown to influence the rate of cleavage of the synthetic peptide by the toxin and these will all determine the sensitivity of detection in endopeptidase assays, but it is also possible that the assay sensitivity was increased by the use of a longer epitope (8 aa) for detecting antibody and its affinity purification.

Another critical factor in determining the sensitivity and specificity of endopeptidase assays is the size of the peptide used as a substrate. A number of studies of the substrate specificity of clostridia neurotoxins suggest that the full-length target proteins are cleaved more efficiently than shorter peptide fragments containing the toxin cleavage sites (Soleilhac et al., 1996; Foran et al., 1994; Shone \& Roberts, 1994). Schmidt \& Bostian (1995) reported detection of higher activity for SNAP$25_{187-203}$ than for the SNAP-25 $5_{167-206}$ peptide in proteolysis by purified BoNT/A in their HPLC assay. However, the $K_{\mathrm{m}}$ for the best substrate was determined as $5.0 \mathrm{mM}$, which is some $10^{7}$ times higher than that determined by other workers for this activity (Niemann et al., 1996). The same authors further showed the SNAP-25 $146-206$ peptide to have only $33 \%$ of activity of the full length SNAP-25. Our own studies with the full length SNAP-25 ${ }_{1-206}$ and SNAP-25 $5_{137-206}$ peptide con-

$2 x ; \square, 3 x ; 0$, in-house reference standard) which had all previously been reduced as described in the text and incubated for $2 \mathrm{~h}$ at $37^{\circ} \mathrm{C}$. Cleaved SNAP-25-MBP was detected using the R2 antibody specific for the cleavage product as described in the Methods. (b) Comparison of the relative potency of 23 different therapeutic preparations of BoNT/A determined using the endopeptidase assay and in vivo bioassays. The regression line $(r=0.95)$ had a slope of 1.03 . 
firmed that these substrates were cleaved by BoNT/A and that the full length protein is the better substrate (Ekong et al., 1997). Although our studies confirmed that the 72-mer peptides used here may not be the optimum for such assays, the high sensitivity achieved with the recombinant peptide described here indicates that there was a good cleavage reaction under the conditions employed and that the sensitivity of the assay was comparable with or better than for the bioassay currently used.

One of the advantages of the in vitro assay described here is its specificity which is defined by the specific cleavage of the target protein by the toxin coupled with specific immunodetection of the cleavage product. Thus Clostridium botulinum toxin type $\mathrm{E}$, which also cleaves SNAP-25 at position Arg $_{180}-$-lle $_{181}$ (Schiavo et al., 1993a), would remain undetected by antibodies selective for type A toxin detection. Potential problems due to crossreactivity with other clostridial neurotoxins should be minimal. However, the presence of other neurotoxins may well interfere with the sensitivity due to the presence of a 9-residue motif, which serves as a common recognition site for all clostridial neurotoxins (Rossetto et al., 1994). This will have to be determined. Furthermore, the observation that Clostridium botulinum type C toxin also cleaves SNAP-25 (Foran et al., 1996; Williamson et al., 1996) at a position close to that cleaved by BoNT/A (Dr O. Dolly, personal communication) has also opened the possibility of interference in mixed preparations. However, the fact that type $\mathrm{C}$ toxin cleaves SNAP-25 at a rate 2000 -fold lower than that of type A toxin (Niemann et al., 1996) suggests this may not present a problem.

In this study we have described a simple microtitrebased assay which utilizes a recombinant fragment of SNAP-25, spanning the BoNT/A toxin cleavage site as substrate, together with targeted anti-peptide antibodies for measuring BoNT/A endopeptidase activity in vitro. The assay is very sensitive, technically simple and rapid and could therefore be used to screen the activities of a large number of samples containing active type A toxin. With a sensitivity greater than that of the mouse bioassay, this assay represents the most sensitive in vitro technique to date for the detection of biologically active BoNT/A toxin. The assay has been shown to be particularly suitable for the detection of BoNT/A in clinical preparations where its use would eliminate the use of large numbers of animals currently required for testing purposes. Clinical preparations containing type A toxin, although not necessarily pure, do not contain other neurotoxin serotypes and are free from protease activities which may compromise the sensitivity of such assays for clinical and poisoning incident specimens. Although the endopeptidase assay described here has advantages over previous in vitro assays for this toxin, a potential limitation of this approach is that no assessment of receptor-binding and internalization activities of the toxin is made. In addition, the assay takes no account of the possible role of phosphorylation on toxin activity (Ferrer-Montiel et al., 1996). It has yet to be determined whether these limitations are likely to compromise the usefulness of the assay to replace the in vivo bioassay procedures. If so, the presence of the receptor binding domain on the toxin could be confirmed by immunodetection with specific antibodies and the phosphorylation status of the toxin could be evaluated as necessary. Clearly, further validation of the endopeptidase assay for toxin detection and its application for monitoring clinical preparations and biological samples is required.

\section{ACKNOWLEDGEMENTS}

This work was supported by a grant from The Home Office under Animal Procedures Research Scheme. The authors are indebted to Dr C. C. Shone from CAMR, Porton Down, Wiltshire, UK, for a gift of pure BoNT/A, Mr C. Gee of Laboratory for Molecular Structure, NIBSC, South Mimms, Potters Bar, UK, for performance of mass spectrometric analysis, Dr D. Pappin of the ICRF, Lincoln's Inn Fields, London, UK, for N-terminal sequence analysis and Ms K. McLellan for performance of bioassays on clinical formulations. We would also like to thank Dr M. J. Corbel and Dr G. Schild for their comments on the manuscript.

\section{REFERENCES}

Balls, M. \& Straughan, D. W: (1996). The three R's of Russell \& Burch and the testing of biological products. Dev Biol Stand 86, 8-11.

Binz, T., Blasi, J., Yamasaki, S., Baumeister, A., Link, E., Sudhof, T. C., Jahn, R. \& Niemann, H. (1994). Proteolysis of SNAP-25 by types A and E botulinal neurotoxins. J Biol Chem 269, 1617-1620.

Blasi, J., Chapman, E. R., Link, E., Binz, T., Yamasaki, S., De Camilli, P., Sudhof, T. C., Niemann, H. \& Jahn, R. (1993). Botulinum neurotoxin A selectively cleaves the synaptic protein SNAP-25. Nature 365, 160-163.

Doellgast, G. J., Triscott, M. X., Beard, A. G., Bottoms, J. D., Cheng, T., Roh, B. H., Roman, M. G., Hall, P. A. \& Brown, J. E. (1993). Sensitive enzyme-linked immunosorbent assay for detection of Clostridium botulinum neurotoxins A, B and E using signal amplification via enzyme-linked coagulation assay. J Clin Microbiol 31, 2402-2409.

Ekong, T. A. N., McLellan, K. \& Sesardic, D. (1995). Immunological detection of Clostridium botulinum toxin type A in therapeutic preparations. J Immunol Methods 180, 181-191.

Ekong, T. A. N., Gee, C., Blasi, J. \& Sesardic, D. (1997). An alternative bioassay for botulinum neurotoxin type $A$ based on its endopeptidase activity. Dev Anim Vet Sci 27, 1039-1045.

Ferrer-Montiel, A. V., Canaves, J. M., DasGupta, B. R., Wilson, M. C. \& Montal, M. (1996). Tyrosine phosphorylation modulates the activity of clostridia neurotoxins. J Biol Chem 271, 18322-18325.

Foran, P., Shone, C. C. \& Dolly, J. O. (1994). Differences in the protease activities of tetanus and botulinum $B$ toxins revealed by the cleavage of vesicle-associated membrane protein and various sized fragments. Biochemistry 33, 15365-15374.

Foran, P., Lawrence, G. W., Shone, C. C., Foster, K. A. \& Dolly, J. O. (1996). Botulinum neurotoxin C1 cleaves both syntaxin and SNAP-25 in intact and permeabilised chromaffin cells : correlation with its blockade of catecholamine release. Biochemistry 35, 2630-2636.

Fukuoka, Y., Tachibana, T. \& Yasui, A. (1993). Expression of 
biologically active $\mathrm{C} 3 \mathrm{a}$ as fusion proteins. Immunol Lett 38, 153-158.

Hallis, B., James, B. A. F. \& Shone, C. C. (1996). Development of novel assays for botulinum type $A$ and $B$ neurotoxins based on their endopeptidase activity. J Clin Microbiol 34, 1934-1938.

Huttner, W. B., Schiebler, W., Greengard, P. \& de Camilli, P. (1983). Synapsin I (Protein I), a nerve terminal-specific phosphoprotein. III. Its association with synaptic vesicles studied in highly purified synaptic vesicle preparation. J Biol Chem 96, 1374-1388.

Jankovic, J. \& Brin, M. F. (1991). Therapeutic uses of botulinum neurotoxin. N Engl J Med 324, 1186-1194.

Kumar, P., Colston, J. T., Chambers, J. P., Rael, E. P. \& Valdes, J. J. (1994). Detection of botulinum toxin using an evanescent wave immunosensor. Biosens Bioelectronics 9, 57-63.

Laemmli, U. K. (1970). Cleavage of structural proteins during the assembly of the head of bacteriophage T4. Nature 227, 680-685.

Li, Y., Foran, P., Fairweather, N. F., de Paiva, A., Weller, U., Dougan, G. \& Dolly, J. O. (1994). A single mutation in the recombinant light chain of tetanus toxin abolishes its proteolytic activity and removes the toxicity seen after reconstitution with native heavy chain. Biochemistry 33, 7014-7020.

Link, E., Edelmann, L., Chou, J. H., Binz, T., Yamasaki, S., Eisel, U., Baumert, M., Sudhof, T. C., Niemann, H. \& Jahn, R. (1992). Tetanus toxin action: inhibition of neurotransmitter release linked to synaptobrevin proteolysis. Biochem Biophys Res Commun 189, 1017-1023.

Mclellan, K., Gaines Das, G. E., Ekong, T. A. N. \& Sesardic, D. (1996). Therapeutic botulinum type A toxin: factors affecting potency. Toxicon 34, 975-985.

Montecucco, C. \& Schiavo, G. (1993). Tetanus and botulinum neurotoxins: a new family of metalloproteases. Trends Biochem Sci 18, 324-327.

Montecucco, C. \& Schiavo, G. (1995). The structure and function of tetanus and botulinum neurotoxins. $Q$ Rev Biophys 28, $423-472$.

Neu, H. C. \& Heppel, L. A. (1965). The release of enzymes from Escherichia coli by osmotic shock and during the formation of spheroplasts. J Biol Chem 240, 3685-3692.

Niemann, H., Hayashi, T., Yamasaki, S., Neuenberg, P., Mannler, P. \& Binz, T. (1996). Toxins and substrates: structural requirements for formation of protein/substrate complexes. In Abstracts of the International Conference for Biomedical Aspects of Clostridial Neurotoxins, Oxford, UK, 1996, Abstract 16.

Oyler, G. A., Higgins, G. A., Hart, R. A., Battenberg, E., Billinsgley, M., Bloom, F. E. \& Wilson, M. C. (1989). The identification of a novel synaptosomal-associated protein, SNAP-25, differentially expressed by neuronal subpopulations. J Biol Chem 109, 30393052.

Pearce, L. B., Borodic, G. E., Johnson, E. A., First, E. R. \& MacCallum, R. D. (1995). The median paralysis unit: a more pharmacologically relevant unit of biologic activity for botulinum toxin. Toxicon 33, 217-227.

Rossetto, O., Schiavo, G., Montecucco, C., Poulain, B., Deloye, F., Lozzi, L. \& Shone, C. C. (1994). SNARE motif and neurotoxins. Nature 372, 415-416.

Sakaguchi, G. (1983). Clostridium botulinum toxins. Pharmacol Ther 19, 165-194.
Schantz, E. J. \& Johnson, E. A. (1992). Properties and use of botulinum toxin and other microbial neurotoxins in medicine. Microbiol Rev 56, 80-99.

Schiavo, G., Benfenati, F., Poulain, B., Rossetto, O., de Laureto, P. P., DasGupta, B. R. \& Montecucco, C. (1992). Tetanus and botulinum $B$ neurotoxins block transmitter release by proteolytic cleavage of synaptobrevin. Nature 359, 832-835.

Schiavo, G., Santucci, A., DasGupta, B. R., Mehta, P. P., Jontes, J., Benfenati, F., Wilson, C. W. \& Montecucco, C. (1993a). Botulinum neurotoxins serotypes $A$ and E cleave SNAP-25 at distinct COOH-terminal peptide bonds. FEBS Lett 335, 99-103.

Schiavo, G., Rossetto, O., Catsicas, S., de Laureto, P. P., DasGupta, B. R. \& Montecucco, C. (1993b). Identification of the nerve terminal targets of botulinum neurotoxin serotypes $A, D$, and $E$. J Biol Chem 268, 23784-23787.

Schmidt, J. J. \& Bostian, K. A. (1995). Proteolysis of synthetic peptides by type A botulinum neurotoxin. J Protein Chem 14, 703-708.

Sesardic, D., McLellan, K., Ekong, T. A. N. \& Gaines Das, R. (1996). Refinement and validation of an alternative bioassay for potency testing of therapeutic botulinum type A toxin. Pharmacol Toxicol 78, 283-288.

Shone, C. C. \& Roberts, A. K. (1994). Peptide substrate specificity and properties of the zinc-endopeptidase activity of botulinum type B neurotoxin. Eur J Biochem 225, 263-270.

Shone, C. C., Wilton-Smith, P., Appleton, N., Hambleton, P., Modi, N., Gatley, S. \& Melling, J. (1985). Monoclonal antibodybased immunoassay for type A Clostridium botulinum toxin is comparable to the mouse bioassay. Appl Environ Microbiol 50, 63-67.

Simpson, L. L. (1981). The origin, structure and pharmacological activity of botulinum toxin. Pharmacol Rev 33, 155-188.

Singh, B. R., Lopes, T. \& Silvia, M. A. (1996). Immunochemical characterization of type A botulinum neurotoxin in its purified and complexed forms. Toxicon 34, 267-275.

Soleilhac, J.-M., Cornille, F., Martin, L., Lenoir, C., Fournie-Zaluski, M.-C. \& Roques, B. P. (1996). A sensitive and rapid fluorescencebased assay for determination of tetanus toxin peptidase activity. Anal Biochem 241, 120-127.

Sölner, T., Whiteheart, S. W., Brunner, M., Erjument-Bromage, H., Geromanos, S., Tempst, P. \& Rothman, J. E. (1993). SNAP receptors implicated in vesicle targeting and fusion. Nature 362 , 318-324.

Towbin, H., Staehelin, T. \& Gordon, J. (1979). Electrophoretic transfer from polyacrylamide gels to nitrocellulose sheets: procedure and some applications. Proc Natl Acad Sci USA 76, $4350-4354$.

Wictome, M., Rossetto, O., Montecucco, C. \& Shone, C. C. (1996). Substrate residues $\mathrm{N}$-terminal to the cleavage site of botulinum type B neurotoxin play a role in determining the specificity of its endopeptidase activity. FEBS Lett 386, 133-136.

Williamson, L. C., Halpern, J. L., Montecucco, C., Brown, J. E. \& Neale, E. A. (1996). Clostridial neurotoxins and substrate proteolysis in intact neurones: Botulinum neurotoxin $\mathrm{C}$ acts on synaptosomal-associated protein of $25 \mathrm{kDa}$. J Biol Chem 271, 7694-7699.

Received 20 May 1997; accepted 30 June 1997. 